\title{
Síntese e determinação da atividade antimicrobiana de derivados 5-nitro- 2-tiofilidênicos frente a Staphylococcus aureus multi-resistente
}

\author{
Andrea Masunari, Leoberto Costa Tavares \\ Laboratório de Planejamento e Desenvolvimento de Fármacos - Departamento de Tecnologia Bioquímico- \\ Farmacêutica, Faculdade de Ciências Farmacêuticas, Universidade de São Paulo
}

L. C. Tavares

Departamento de Tecnologia

Bioquímico-Farmacêutica

Faculdade de Ciências

Farmacêuticas - FCF/USP

Av. Prof. Lineu Prestes n. 580,

05505-900 - São Paulo, SP - Brasil

E-mail: leoberto@usp.br
O elevado nível de resistência que cepas de Staphylococcus aureus vêm apresentando aos antibióticos atualmente disponíveis caracterizase como grave problema em âmbito mundial e com consequências que beiram à fatalidade. Com a atenção voltada para este fenômeno, quatorze derivados 5-nitro-2-tiofilidênicos foram sintetizados e testados quanto à atividade antimicrobiana frente a cepas padrão (ATCC 25923) e multi-resistente (3SP/R33) de Staphylococcus aureus. Todos os compostos testados apresentaram excelente atividade bacteriostática e, alguns entre eles, atividade bactericida. A 5-nitro-2-tiofilideno-4acetilbenzidrazida se mostrou como o composto mais ativo com concentração inibitória equivalente a $0,14 \mathrm{mg} / \mathrm{mL}$. A partir dos resultados obtidos evidenciou-se oforte potencial de derivados 5-nitro2-tiofilidênicos como possível alternativa para o desenvolvimento de novos fármacos com atividade antimicrobiana.

\section{INTRODUÇÃO}

O controle de infecções causadas por microrganismos multi-resistentes é considerado, atualmente, grande prioridade entre os epidemiologistas, uma vez que estas têm se mostrado muito virulentas e de difícil tratamento. Um grande foco de desenvolvimento de resistência bacteriana são os ambientes hospitalares, sendo este fenômeno resultado da coincidência de fatores como presença de outras infecções, depressão imunológica e grande facilidade de transmissão.

Até as infecções causadas pelo gênero estafilococos, antes facilmente controláveis, vêm se constituindo, nas últimas décadas, em grande ameaça à Saúde Pública em função do surgimento de cepas com amplo espectro de resistência (Nishi, 1998; Crowcroft, 1999; Onorato, 1999; Fuchs et al., 2002; Brenwald, Fraise, 2003; Maudsley et al., 2004).
Na busca de novos antimicrobianos que sejam eficazes no tratamento de infecções causadas por bactérias multi-resistentes consideram-se basicamente a descoberta de novos alvos e a potencialização da atividade de compostos com atividade antimicrobiana conhecida (Fernandes et al., 1999). Com o constante avanço na área de modificação molecular ao longo dos últimos anos, a segunda alternativa mostra-se altamente viável e com grande perspectiva de sucesso, já que estudos que visam o planejamento e desenvolvimento de fármacos têm mostrado alta aplicabilidade nas mais diversas áreas de saúde. Além disso, vale ressaltar que este tipo de metodologia mostra-se claramente mais vantajosa tanto em termos de investimentos como em relação ao tempo de execução, já que a descoberta de um fármaco completamente novo chega a custar, em média, cerca de quinhentos milhões de dólares e pode levar até quinze anos de estudos desde a sua 
concepção até o início dos testes clínicos (Hansch, Leo, 1995; Wermuth, 2000; Barreiro, Fraga, 2001; Rezende et al., 2002; Masunari, Rezende, Tavares, 2004).

Muito tem sido feito, mas ainda são poucos os resultados efetivamente aplicáveis no tratamento de infecções com caráter de multi-resistência. Infecções causadas por cepas resistentes de Staphylococcus aureus não se caracterizam como fenômeno isolado ou exclusivo de países de baixa renda, uma vez que se observa número crescente de estudos relacionados à epidemiologia deste microorganismo em centros que comportam pacientes imunocomprometidos (Lizioli et al., 2003), que sofreram intervenção cirúrgica (McDonald et al., 2003), que foram transplantados (Desai et al, 2003) ou que são portadores de queimaduras graves (Fuchs et al., 2002). Notase ainda, uma grande preocupação da comunidade científica em estabelecer possíveis alternativas relacionadas ao controle e prevenção da colonização por MRSA (Methicillin-Resistant Staphylococcus aureus) em hospitais de todo o mundo, ressaltando a gravidade e a necessidade de busca de soluções para este problema (Burd et al., 2003; Rohr et al., 2003).

Entre as classes de agentes antimicrobianos atualmente disponíveis, grande interesse tem sido despertado por alguns fármacos da classe dos nitrofuranos, não apenas pelo fato de estes compostos apresentarem amplo espectro de ação, como também pela incapacidade de indução ao desenvolvimento de resistência bacteriana importante (Dayan, Deguingard, Truzman, 1985; Petri Jr., 2001).

Tavares e colaboradores (Tavares et al., 1999a, b) mostraram que modificações estruturais na molécula da nifuroxazida, 5-nitro-2-furfurilideno-4-hidroxibenzidrazida (figura 1), como substituição da hidroxila fenólica por grupos aceptores de elétrons e substituição do anel furânico por tiofênico, favoreceram de forma significativa a atividade antimicrobiana desta série de compostos (Tavares et al., 1999a).

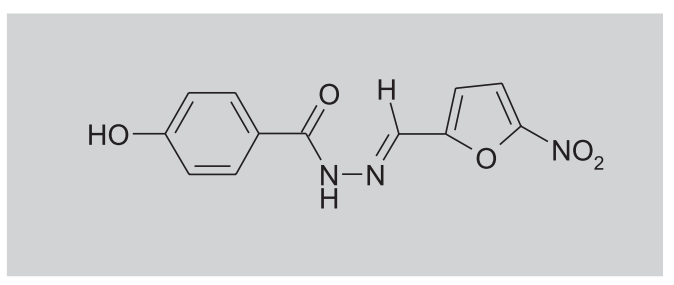

FIGURA 1 - Estrutura química da nifuroxazida.

Assim, com a atenção voltada para este problema, realizaram-se a síntese, a identificação e testes de atividade antimicrobiana frente à MRSA de quatorze derivados 5-nitro2-tiofilidênicos, com estruturas análogas à nifuroxazida. $\mathrm{O}$ padrão de substituição selecionado neste trabalho envolveu a introdução estratégica de grupos substituintes no anel benzênico, baseando-se em faixa de hidrofobicidade ótima (valores de $\pi$ entre 0,70 e 1,55), anteriormente por nós determinada, por aplicação da metodologia de Topliss (1972). Considerou-se ainda, variações de efeito eletrônico dos grupos selecionados fundamentando sua escolha no diagrama de Craig (1971).

As 5-nitro-2-tiofilidenobenzidrazidas (1 a 14) foram obtidas em três etapas, conforme se pode observar na figura 2. Inicialmente os ácidos benzóicos foram transformados em ésteres, os ésteres metílicos foram submetidos à reação com hidrazina para conduzir às respectivas benzidrazidas $\mathrm{e}$, finalmente, por reação das benzidrazidas com o 5-nitro-2tiofenocarboxaldeído foram obtidos os derivados 1 a 14.

A avaliação da atividade antimicrobiana dos derivados 5-nitro-2-tiofilidênicos foi feita por meio da determinação da concentração inibitória mínima frente às cepas padrão (ATCC 25923) e multi-resistente (3SP/R33) de Staphylococcus aureus (Oliveira et al., 2001). A maioria dos derivados em estudo apresentou excelente atividade antimicrobiana.

\section{MATERIAL E MÉTODOS}

\section{Síntese e identificação de 5-nitro-2-tiofilideno benzidrazidas}

A determinação da faixa de fusão dos compostos foi efetuada em lamínulas de vidro, utilizando-se aparelho digital de marca Micro Química, modelo MQAPF-301. A análise elementar dos derivados 5-nitro-2-tiofilidênicos foi realizada em aparelho Perkin Elmer Elemental Analyser 2400 CHN. Os espectros de absorção na região do Infravermelho foram obtidos em espectrofotômetro Shimadzu-470, utilizando-se dispersão em brometo de potássio (Aldrich Chemical Company, Inc.). Os espectros de ressonância magnética nuclear de hidrogênio $\left(\mathrm{RMN}^{1} \mathrm{H}\right)$ e de carbono treze $\left(\mathrm{RMN}{ }^{13} \mathrm{C}\right)$ foram efetuados em espectrofotômetro Bruker, modelo Advance DPX-300MHz, utilizando-se dimetilsulfóxido deuterado (DMSO-d 6 99,5\%-Aldrich Chemical Company, Inc.) como solvente e tetrametilsilano (TMS) como padrão de referência interna.

Obtenção de benzoatos de metila (Tavares, 1999a). Dissolveu-se o ácido benzóico adequado em excesso de metanol anidro e quantidade catalítica de ácido sulfúrico concentrado, mantendo o sistema em refluxo por um período de aproximadamente quatro horas. Reduziu-se o volume de solvente pela metade, utilizando-se rotaevaporador. O éster resultante foi cristalizado por meio de resfriamento. Os cristais obtidos foram filtrados, lavados com água destilada e secos. Comprovou-se a identidade química dos 
ésteres por análise espectrométrica na região do Infravermelho (IV). Determinou-se a faixa de fusão dos compostos como critério indicativo do seu grau de pureza. Obtenção de benzidrazidas (Tavares, 1999a). Aqueceu-se, sob agitação magnética constante, solução de hidrato de hidrazina $64 \%$ até $50-60{ }^{\circ} \mathrm{C}$. Adicionaram-se pequenas porções do benzoato de metila adequado à mistura, aquecendo-a, em seguida, até refluxo durante aproximadamente dez minutos. Submeteu-se o sistema a resfriamento sucessivo em banho de água, banho de gelo e banho de gelo seco e etanol. Formaram-se cristais que foram separados por filtração, lavados com água destilada gelada e secados. Comprovou-se a identidade química dos compostos por análise espectrométrica na região do IV. Determinou-se a faixa de fusão das benzidrazidas como critério indicativo do seu grau de pureza.

Obtenção das 5-nitro-2-tiofilideno benzidrazidas (Tavares, 1999a). Adicionou-se, sob agitação constante, 5nitro-2-tiofenocarboxaldeído à mistura de água destilada, ácido sulfúrico concentrado, ácido acético glacial e metanol na proporção de 8:7:8:20, respectivamente. Aqueceu-se até temperatura de refluxo e procedeu-se à adição lenta, em pequenas porções, da benzidrazida adequada na forma sólida. Formou-se sólido amorfo que foi filtrado, lavado com água deionizada gelada e seco. Comprovou-se a identidade química das bases de Schiff por análises espectrométricas na região do IV, RMN ${ }^{1} \mathrm{H}$ e RMN ${ }^{13} \mathrm{C}$. A determinação da faixa de fusão e a análise elementar indicaram alto grau de pureza das 5-nitro-2-tiofilideno benzidrazidas.

\section{5-nitro-2-tiofilidenobenzidrazida (1)}

$\left(\mathrm{C}_{12} \mathrm{H}_{9} \mathrm{O}_{3} \mathrm{~N}_{3} \mathrm{~S}\right)$ Sólido amorfo amarelo escuro. Rendimento: $93 \%$; F.f.: $246,5-247,3^{\circ} \mathrm{C}$

IV (KBr): v $\left(\mathrm{cm}^{-1}\right) 3250\left(\mathrm{v}_{\mathrm{N}-\mathrm{H}}\right) ; 3100\left(\mathrm{v}_{\mathrm{C}-\mathrm{H}}\right) ; 1645\left(\mathrm{v}_{\mathrm{C}=\mathrm{O}}\right)$; 1595 e $1486\left(\mathrm{v}_{\mathrm{C}=\mathrm{C}}\right) ; 1542\left(\delta_{\mathrm{N}-\mathrm{H}}\right) ; 1521\left(\mathrm{v}_{\mathrm{N}=\mathrm{O} \text { ass }}\right) ; 1330$ $\left(\mathrm{v}_{\mathrm{N}=\mathrm{O} \operatorname{sim}}\right) ; 701\left(\mathrm{~d}_{\mathrm{C}-\mathrm{H}}\right) ; 628\left(\mathrm{v}_{\mathrm{C}-\mathrm{S}}\right)$.

$\mathbf{R M N}^{1} \mathbf{H}: \delta 12,25\left(\mathrm{~s}, 1 \mathrm{H}, \mathrm{H}_{8}\right) ; 8,69\left(\mathrm{~s}, 1 \mathrm{H}, \mathrm{H}_{6}\right) ; 8,15(\mathrm{~d}$, $\left.1 \mathrm{H}, \mathrm{H}_{4}, J=4,24 \mathrm{~Hz}\right) ; 7,91\left(\mathrm{~d}, 2 \mathrm{H}, \mathrm{H}_{11}\right.$ e $\left.\mathrm{H}_{15}, J=7,03 \mathrm{~Hz}\right)$; 7,52-7,65 (m, 4H, $\mathrm{H}_{3}, \mathrm{H}_{12}, \mathrm{H}_{13}$ e $\left.\mathrm{H}_{14}\right)$.

RMN ${ }^{13} \mathbf{C}: \delta 163,14\left(\mathrm{C}_{9}\right) ; 147,54\left(\mathrm{C}_{2}\right) ; 142,02\left(\mathrm{C}_{6}\right) ; 133,64$ $\left(\mathrm{C}_{5}\right) ; 133,06\left(\mathrm{C}_{4}\right) ; 131,39\left(\mathrm{C}_{10}\right) ; 130,57\left(\mathrm{C}_{13}\right) ; 129,47$ $\left(\mathrm{C}_{11}\right.$ e $\left.\mathrm{C}_{15}\right) ; 128,59\left(\mathrm{C}_{12}\right.$ e $\left._{14}\right) ; 114,74\left(\mathrm{C}_{3}\right)$.

AE: C: $49,29 \%\left(49,14 \%_{\text {calc. }}\right)$; H: 3,45\% $\left(3,09 \%{ }_{\text {calc. }}\right)$; N: $14,66 \%\left(4,32 \%{ }_{\text {calc. }}\right)$.

\section{5-nitro-2-tiofilideno-4-clorobenzidrazida (2)}

$\left(\mathrm{C}_{12} \mathrm{H}_{8} \mathrm{O}_{3} \mathrm{~N}_{3} \mathrm{SCl}\right)$. Sólido amorfo laranja escuro. Rendimento: $96 \%$; F.f.: $288,1-290,1^{\circ} \mathrm{C}$

IV (KBr): $v\left(\mathrm{~cm}^{-1}\right) 3255\left(\mathrm{v}_{\mathrm{N}-\mathrm{H}}\right) ; 3100\left(\mathrm{v}_{\mathrm{C}-\mathrm{H}}\right) ; 1646\left(\mathrm{v}_{\mathrm{C}=\mathrm{O}}\right)$; 1589 e $1487\left(\mathrm{v}_{\mathrm{C}=\mathrm{C}}\right) ; 1551\left(\delta_{\mathrm{N}-\mathrm{H}}\right) ; 1523\left(\mathrm{v}_{\mathrm{N}=\mathrm{O} \text { ass. }}\right) ; 1331$ $\left(v_{\mathrm{N}=\mathrm{O} \text { sim. }}\right) ; 1110\left(\mathrm{v}_{\mathrm{C}-\mathrm{Cl}}\right) ; 725\left(\delta_{\mathrm{C}-\mathrm{H}}\right) ; 632\left(\mathrm{v}_{\mathrm{C}-\mathrm{S}}\right)$.
RMN ${ }^{1} \mathbf{H}: \delta 12,28\left(\mathrm{~s}, 1 \mathrm{H}, \mathrm{H}_{8}\right) ; 8,68\left(\mathrm{~s}, 1 \mathrm{H}, \mathrm{H}_{6}\right) ; 8,14(\mathrm{~d}$, $\left.1 \mathrm{H}, \mathrm{H}_{4}, J=4,25 \mathrm{~Hz}\right) ; 7,94$ (d, $2 \mathrm{H} \mathrm{H}_{11}$ e $_{15}, J=8,22 \mathrm{~Hz}$ ); 7,59-7,64 (m, 3H, $\mathrm{H}_{3}, \mathrm{H}_{12}$ e $\left.\mathrm{H}_{14}\right)$.

RMN ${ }^{13} \mathbf{C}: \delta 162,45\left(\mathrm{C}_{9}\right) ; 151,08\left(\mathrm{C}_{6}\right) ; 146,70\left(\mathrm{C}_{2}\right) ; 141,67$ $\left(\mathrm{C}_{13}\right) ; 137,15\left(\mathrm{C}_{5}\right) ; 131,75\left(\mathrm{C}_{10}\right) ; 131,70\left(\mathrm{C}_{4}\right) ; 130,62$ $\left(\mathrm{C}_{12}\right.$ e $\left.\mathrm{C}_{14}\right) ; 129,83\left(\mathrm{C}_{11}\right.$ e $\left.\mathrm{C}_{15}\right) ; 128,83\left(\mathrm{C}_{3}\right)$

AE: C: $46,44 \%\left(46,54 \%_{\text {calc }}\right) ; \mathrm{H}: 2,97 \%\left(2,60 \%_{\text {calc. }}\right)$; N: $13,48 \%\left(13,57 \%_{\text {calc. }}\right)$.

5-nitro-2-tiofilideno-3,4-diclorobenzidrazida (3) $\left(\mathrm{C}_{12} \mathrm{H}_{7} \mathrm{O}_{3} \mathrm{~N}_{3} \mathrm{SCl}_{2}\right)$ Sólido amorfo laranja escuro. Rendimento: $98 \%$; F.f.: $222,1-225,5^{\circ} \mathrm{C}$

IV (KBr): v $\left(\mathrm{cm}^{-1}\right) 3360\left(\mathrm{v}_{\mathrm{N}-\mathrm{H}}\right) ; 3185\left(\mathrm{v}_{\mathrm{C}-\mathrm{H}}\right) ; 1640\left(\mathrm{v}_{\mathrm{C}=\mathrm{O}}\right)$; 1595 e $1497\left(\mathrm{v}_{\mathrm{C}=\mathrm{C}}\right) ; 1564\left(\delta_{\mathrm{N}-\mathrm{H}}\right) ; 1526\left(\mathrm{v}_{\mathrm{N}=\mathrm{O} \text { ass }}\right) ; 1332$ $\left(\mathrm{v}_{\mathrm{N}=\mathrm{O} \text { sim }}\right) ; 1069\left(\mathrm{v}_{\mathrm{C}-\mathrm{Cl}}\right) ; 742\left(\delta_{\mathrm{C}-\mathrm{H}}\right) ; 673\left(\mathrm{v}_{\mathrm{C}-\mathrm{S}}\right)$.

$\mathbf{R M N}^{1} \mathbf{H}: \delta 12,30\left(\mathrm{~s}, 1 \mathrm{H}, \mathrm{H}_{8}\right) ; 8,58\left(\mathrm{~s}, 1 \mathrm{H}, \mathrm{H}_{6}\right) ; 8,14(\mathrm{~d}$, $\left.1 \mathrm{H}, \mathrm{H}_{4}, J=4,18 \mathrm{~Hz}\right) ; 7,80$ (d, $2 \mathrm{H}, \mathrm{H}_{11}$ e $_{15}, J=8,12 \mathrm{~Hz}$ ); 7,79-7,81 (m, 1H, $\left.\mathrm{H}_{12}\right), 7,56\left(\mathrm{~d}, 1 \mathrm{H}, \mathrm{H}_{3}, J=4,18 \mathrm{~Hz}\right)$.

RMN ${ }^{13} \mathbf{C}: \delta 161,98\left(\mathrm{C}_{9}\right) ; 151,93\left(\mathrm{C}_{6}\right) ; 147,16\left(\mathrm{C}_{2}\right) ; 142,73$ $\left(\mathrm{C}_{13}\right) ; 135,82$ e 131,88 $\left(\mathrm{C}_{12}\right.$ e $\left._{14}\right) ; 134,04\left(\mathrm{C}_{5}\right) ; 132,35\left(\mathrm{C}_{10}\right)$; 131,37 e $130,98\left(\mathrm{C}_{11}\right.$ e $\left._{15}\right) ; 130,46\left(\mathrm{C}_{4}\right) ; 128,97\left(\mathrm{C}_{3}\right)$.

AE: C: $40,01 \%\left(39,79 \%_{\text {calc. }}\right)$; H: 2,62\% (1,95\% calc. $\left._{2}\right)$; N: $11,82 \%\left(11,60 \% \%_{\text {calc. }}\right)$.

\section{5-nitro-2-tiofilideno-4-iodobenzidrazida (4)}

$\left(\mathrm{C}_{12} \mathrm{H}_{8} \mathrm{O}_{3} \mathrm{~N}_{3} \mathrm{SI}\right)$ Sólido amorfo amarelo escuro. Rendimento: $95 \%$; F.f.: $276,5-277,9^{\circ} \mathrm{C}$

IV (KBr): $v\left(\mathrm{~cm}^{-1}\right) 3160\left(\mathrm{v}_{\mathrm{N}-\mathrm{H}}\right) ; 3025\left(\mathrm{v}_{\mathrm{C}-\mathrm{H}}\right) ; 1643\left(\mathrm{v}_{\mathrm{C}=\mathrm{O}}\right)$; 1590 e $1495\left(\mathrm{v}_{\mathrm{C}=\mathrm{C}}\right) ; 1557\left(\delta_{\mathrm{N}-\mathrm{H}}\right) ; 1530\left(\mathrm{~V}_{\mathrm{N}=\mathrm{O} \text { assim. }}\right) ; 1320$ $\left(\mathrm{v}_{\mathrm{N}=\mathrm{O} \operatorname{sim}}\right) ; 1005\left(\mathrm{v}_{\mathrm{C}-\mathrm{I}}\right) ; 728\left(\delta_{\mathrm{C}-\mathrm{H}}^{\mathrm{N}-\mathrm{H}}\right) ; 680\left(\mathrm{v}_{\mathrm{C}-\mathrm{S}}\right)$

RMN ${ }^{1} \mathbf{H}: \delta 12,15\left(\mathrm{~s}, 1 \mathrm{H}, \mathrm{H}_{8}\right) ; 8,67\left(\mathrm{~s}, 1 \mathrm{H}, \mathrm{H}_{6}\right) ; 8,14(\mathrm{~d}, 1 \mathrm{H}$, $\left.\mathrm{H}_{4}, J=4,23 \mathrm{~Hz}\right) ; 7,94$ (d, 2H, $\mathrm{H}_{11}$ e $\left.\mathrm{H}_{15}, J=8,20 \mathrm{~Hz}\right) ; 7,69$ (d, $\left.2 \mathrm{H}, \mathrm{H}_{12} \mathrm{e} \mathrm{H}_{14}, J=8,20 \mathrm{~Hz}\right) ; 7,60\left(\mathrm{~d}, 1 \mathrm{H}, \mathrm{H}_{3}, J=4,23 \mathrm{~Hz}\right)$. RMN ${ }^{13} \mathbf{C}: \delta 162,70\left(\mathrm{C}_{9}\right) ; 146,50\left(\mathrm{C}_{6}\right) ; 146,48\left(\mathrm{C}_{13}\right)$; $141,45\left(\mathrm{C}_{5}\right) ; 137,36\left(\mathrm{C}_{2}\right) ; 130,51\left(\mathrm{C}_{12} \mathrm{e} \mathrm{C}_{14}\right) ; 129,94\left(\mathrm{C}_{10}\right)$; $129,53\left(\mathrm{C}_{11}\right.$ e $\left.\mathrm{C}_{15}\right) ; 126,01\left(\mathrm{C}_{4}\right) ; 125,05\left(\mathrm{C}_{3}\right)$.

AE: C: $36,03 \%\left(35,92 \%_{\text {calc }}\right) ; \mathrm{H}: 1,92 \%\left(2,01 \%_{\text {calc. }}\right) ; \mathrm{N}$ : $10,42 \%\left(10,47 \%_{\text {calc. }}\right)$.

\section{5-nitro-2-tiofilideno-4-bromobenzidrazida (5)}

$\left(\mathrm{C}_{12} \mathrm{H}_{8} \mathrm{O}_{3} \mathrm{~N}_{3} \mathrm{SBr}\right)$ Sólido amorfo amarelo escuro. Rendimento: $92 \%$; F.f.: $274,4-276,5^{\circ} \mathrm{C}$

IV (KBr): v $\left(\mathrm{cm}^{-1}\right) 3345\left(\mathrm{v}_{\mathrm{N}-\mathrm{H}}\right) ; 3160\left(\mathrm{v}_{\mathrm{C}-\mathrm{H}}\right) ; 1653\left(\mathrm{v}_{\mathrm{C}=\mathrm{O}}\right)$; 1602 e $1490\left(\mathrm{v}_{\mathrm{C}=\mathrm{C}}\right) ; 1554\left(\delta_{\mathrm{N}-\mathrm{H}}\right) ; 1528\left(\mathrm{v}_{\mathrm{N}=\mathrm{O} \text { ass }}\right) ; 1333$ $\left(\mathrm{v}_{\mathrm{N}=\mathrm{O} \text { sim }}\right) ; 1037\left(\mathrm{v}_{\mathrm{C}-\mathrm{Br}}\right) ; 812\left(\delta_{\mathrm{C}-\mathrm{H}}^{\mathrm{N}}\right) ; 630\left(\mathrm{v}_{\mathrm{C}-\mathrm{S}}\right)$.

RMN $^{1} \mathbf{H}: \delta 12,10\left(\mathrm{~s}, 1 \mathrm{H}, \mathrm{H}_{8}\right) ; 8,58\left(\mathrm{~s}, 1 \mathrm{H}, \mathrm{H}_{6}\right) ; 8,00(\mathrm{~d}, 1 \mathrm{H}$, $\left.\mathrm{H}_{4}, J=4,22 \mathrm{~Hz}\right) ; 7,81$ (d, 2H, $\mathrm{H}_{11}$ e $\left._{15}, J=8,20 \mathrm{~Hz}\right) ; 7,67$ (d, $\left.2 \mathrm{H}, \mathrm{H}_{12} \mathrm{e} \mathrm{H}_{14}, J=8,20 \mathrm{~Hz}\right) ; 7,56\left(\mathrm{~d}, 1 \mathrm{H}, \mathrm{H}_{3}, J=4,22 \mathrm{~Hz}\right)$. RMN ${ }^{13} \mathbf{C}: \delta 163,30\left(\mathrm{C}_{9}\right) ; 151,81\left(\mathrm{C}_{6}\right) ; 147,41\left(\mathrm{C}_{2}\right) ; 142,35$ $\left(\mathrm{C}_{13}\right) ; 132,65\left(\mathrm{C}_{12}\right.$ e $\left.\mathrm{C}_{14}\right) ; 131,40\left(\mathrm{C}_{5}\right) ; 130,69\left(\mathrm{C}_{10}\right) ; 129,58$ $\left(\mathrm{C}_{11} \mathrm{e} \mathrm{C}_{15}\right) ; 126,88\left(\mathrm{C}_{4}\right) ; 126,29\left(\mathrm{C}_{3}\right)$. 
AE: C: $41,12 \%\left(40,69 \%_{\text {calc. }}\right) ; \mathrm{H}: 2,23 \%\left(2,28 \%{ }_{\text {calc. }}\right)$; N: $12,42 \%\left(11,86 \%_{\text {calc. }}\right)$.

\section{5-nitro-2-tiofilideno-4-propilbenzidrazida (6)}

$\left(\mathrm{C}_{15} \mathrm{H}_{15} \mathrm{O}_{3} \mathrm{~N}_{3} \mathrm{~S}\right)$ Sólido amorfo amarelo escuro. Rendimento: $93 \%$; F.f.: $200,5-201,6^{\circ} \mathrm{C}$

IV (KBr): v $\left(\mathrm{cm}^{-1}\right) 3210\left(\mathrm{v}_{\mathrm{N}-\mathrm{H}}\right) ; 3110\left(\mathrm{v}_{\mathrm{C}-\mathrm{H}}\right) ; 1650\left(\mathrm{v}_{\mathrm{C}=\mathrm{O}}\right)$; 1611 e $1509\left(\mathrm{v}_{\mathrm{C}=\mathrm{C}}\right) ; 1556\left(\delta_{\mathrm{N}-\mathrm{H}}\right) ; 1534\left(\mathrm{v}_{\mathrm{N}=\mathrm{O} \text { ass. }}\right) ; 1466$ $\left(\delta_{\mathrm{CH} 2}\right) ; 1375\left(\delta_{\mathrm{CH} 3}\right) ; 1341\left(\mathrm{v}_{\mathrm{N}=\mathrm{O} \text { sim }}\right) ; 814\left(\delta_{\mathrm{C}-\mathrm{H}}\right) ; 690\left(\mathrm{v}_{\mathrm{C}-\mathrm{S}}\right)$. RMN ${ }^{1} \mathrm{H}: \delta 12,14\left(\mathrm{~s}, 1 \mathrm{H}, \mathrm{H}_{8}\right) ; 8,65\left(\mathrm{~s}, 1 \mathrm{H}, \mathrm{H}_{6}\right) ; 8,08(\mathrm{~d}$, $\left.1 \mathrm{H}, \mathrm{H}_{4}, J=4,29 \mathrm{~Hz}\right) ; 7,80$ (d, $2 \mathrm{H}, \mathrm{H}_{11}$ e $\mathrm{H}_{15}, J=8,04 \mathrm{~Hz}$ ); 7,52 (d, $\left.1 \mathrm{H}, \mathrm{H}_{3}, J=4,29 \mathrm{~Hz}\right) ; 7,32\left(\mathrm{~d}, 2 \mathrm{H}, \mathrm{H}_{12}\right.$ e $\mathrm{H}_{14}, J=$ $8,04 \mathrm{~Hz}$ ); 2,59 (t, 2H, $\mathrm{CH}_{2}, J=7,30 \mathrm{~Hz}$ ); 1,60 (sexteto, $2 \mathrm{H}$, $\left.\mathrm{CH}_{2}, J=7,30 \mathrm{~Hz}\right) ; 0,87$ (t, 3H, $\left.\mathrm{CH}_{3}, J=7,30 \mathrm{~Hz}\right)$.

RMN ${ }^{13} \mathbf{C}: \delta 163,32\left(\mathrm{C}_{9}\right) ; 150,76\left(\mathrm{C}_{6}\right) ; 140,85\left(\mathrm{C}_{5}\right) ; 146,90$ $\left(\mathrm{C}_{2}\right) ; 146,83\left(\mathrm{C}_{13}\right) ; 130,48\left(\mathrm{C}_{12}\right.$ e C $\left._{14}\right) ; 129,49\left(\mathrm{C}_{10}\right) ; 128,49$ $\left(\mathrm{C}_{11} \mathrm{e} \mathrm{C}_{15}\right) ; 127,81\left(\mathrm{C}_{4}\right) ; 125,48\left(\mathrm{C}_{3}\right) ; 64,25\left(\mathrm{CH}_{2}\right) ; 25,89$ $\left(\mathrm{CH}_{2}\right) ; 10,28\left(\mathrm{CH}_{3}\right)$.

AE: C: $57,10 \%\left(56,77 \%_{\text {calc. }}\right) ; \mathrm{H}: 4,90 \%\left(4,76 \%_{\text {calc. }}\right)$; $\mathrm{N}: 13,33 \%\left(13,24 \%_{\text {calc }}\right)$.

\section{5-nitro-2-tiofilideno-4-isopropilbenzidrazida (7)}

$\left(\mathrm{C}_{15} \mathrm{H}_{15} \mathrm{O}_{3} \mathrm{~N}_{3} \mathrm{~S}\right)$ Sólido amorfo amarelo escuro. Rendimento: $90 \%$; F.f.: $251,3-252,7^{\circ} \mathrm{C}$

IV (KBr): v $\left(\mathrm{cm}^{-1}\right) 3270\left(\mathrm{v}_{\mathrm{N}-\mathrm{H}}\right) ; 3080\left(\mathrm{v}_{\mathrm{C}-\mathrm{H}}\right) ; 1652\left(\mathrm{v}_{\mathrm{C}=\mathrm{O}}\right)$; 1605 e $1495\left(\mathrm{v}_{\mathrm{C}=\mathrm{C}}\right) ; 1566\left(\delta_{\mathrm{N}-\mathrm{H}}\right) ; 1524\left(\mathrm{v}_{\mathrm{N}=\mathrm{O} \text { ass. }}\right) ; 1381$ $\left(\delta_{\mathrm{CH} 3}\right) ; 1331\left(\mathrm{v}_{\mathrm{N}=\mathrm{O} \text { sim }}\right) ; 708\left(\delta_{\mathrm{C}-\mathrm{H}}\right) ; 670\left(\mathrm{v}_{\mathrm{C}-\mathrm{S}}\right)$.

RMN ${ }^{1} \mathbf{H}: \delta 12,08\left(\mathrm{~s}, 1 \mathrm{H}, \mathrm{H}_{8}\right) ; 8,59\left(\mathrm{~s}, 1 \mathrm{H}, \mathrm{H}_{6}\right) ; 8,04(\mathrm{~d}$, $\left.1 \mathrm{H}, \mathrm{H}_{4}, J=4,32 \mathrm{~Hz}\right) ; 7,75$ (d, 2H, $\mathrm{H}_{11}$ e $\left.\mathrm{H}_{15}, J=8,12 \mathrm{~Hz}\right)$; 7,32 (d, 2H, $\left.\mathrm{H}_{12} \mathrm{e} \mathrm{H}_{14}, J=8,12 \mathrm{~Hz}\right) ; 7,49\left(\mathrm{~d}, 1 \mathrm{H}, \mathrm{H}_{3}, J=\right.$ $4,32 \mathrm{~Hz}$ ); 2,88 (septeto, $1 \mathrm{H}, \mathrm{CH}, J=6,87 \mathrm{~Hz}$ ); 1,14 (d, $6 \mathrm{H}$, $\left.2 \mathrm{CH}_{3}, J=6,87 \mathrm{~Hz}\right)$.

RMN ${ }^{13} \mathbf{C}: \delta 164,15\left(\mathrm{C}_{9}\right) ; 153,80\left(\mathrm{C}_{6}\right) ; 151,62\left(\mathrm{C}_{2}\right) ; 147,73$ $\left(\mathrm{C}_{13}\right) ; 141,76\left(\mathrm{C}_{5}\right) ; 131,39\left(\mathrm{C}_{10}\right) ; 131,31\left(\mathrm{C}_{12} \mathrm{e} \mathrm{C}_{14}\right) ; 130,40$ $\left(\mathrm{C}_{11}\right.$ e $\left._{15}\right) ; 128,76\left(\mathrm{C}_{4}\right) ; 127,36\left(\mathrm{C}_{3}\right) ; 34,32(\mathrm{CH}) ; 24,45$ $\left(2 \mathrm{CH}_{3}\right)$.

AE: C: $57,02 \%\left(56,77 \%_{\text {calc }}\right)$; H: 4,81\% $\left(4,76 \%_{\text {calc. }}\right) ; \mathrm{N}$ : $13,29 \%\left(13,24 \%_{\text {calc }}\right)$

\section{5-nitro-2-tiofilideno-4-propoxibenzidrazida (8)}

$\left(\mathrm{C}_{15} \mathrm{H}_{15} \mathrm{O}_{4} \mathrm{~N}_{3} \mathrm{~S}\right)$ Sólido amorfo amarelo escuro. Rendimento: $93 \%$; F.f.: $195,7-197,2^{\circ} \mathrm{C}$

IV (KBr): $v\left(\mathrm{~cm}^{-1}\right) 3290\left(\mathrm{v}_{\mathrm{N}-\mathrm{H}}\right) ; 3105\left(\mathrm{v}_{\mathrm{C}-\mathrm{H}}\right) ; 1659\left(\mathrm{v}_{\mathrm{C}=\mathrm{O}}\right)$; 1607 e $1507\left(\mathrm{v}_{\mathrm{C}=\mathrm{C}}\right) ; 1571\left(\delta_{\mathrm{N}-\mathrm{H}}\right) ; 1528\left(\mathrm{v}_{\mathrm{N}=\mathrm{O} \text { ass. }}\right) ; 1470$ $\left(\delta_{\mathrm{CH}_{2}}\right) ; 1391\left(\delta_{\mathrm{CH} 3}\right) ; 1337\left(\mathrm{v}_{\mathrm{N}=\mathrm{O} \text { sim }}\right) ; 1256\left(\mathrm{v}_{\mathrm{C}-\mathrm{O}}\right) ; 729\left(\delta_{\mathrm{C}-\mathrm{H}}\right)$; $680\left(v_{\mathrm{C}-\mathrm{S}}\right)$.

RMN ${ }^{1} \mathbf{H}: \delta 12,12\left(\mathrm{~s}, 1 \mathrm{H}, \mathrm{H}_{8}\right) ; 8,67\left(\mathrm{~s}, 1 \mathrm{H}, \mathrm{H}_{6}\right) ; 8,13(\mathrm{~d}$, $\left.1 \mathrm{H}, \mathrm{H}_{4}, J=4,29 \mathrm{~Hz}\right) ; 7,90$ (d, $2 \mathrm{H}, \mathrm{H}_{11}$ e $\mathrm{H}_{15}, J=8,54 \mathrm{~Hz}$ ); 7,07 (d, 2H, $\mathrm{H}_{12}$ e $\left._{14}, J=8,54 \mathrm{~Hz}\right) ; 7,56\left(\mathrm{~d}, 1 \mathrm{H}, \mathrm{H}_{3}, J=\right.$ $4,29 \mathrm{~Hz}$ ); 4,02 (t, 2H, $\mathrm{CH}_{2}, J=6,94 \mathrm{~Hz}$ ); 1,76 (sexteto, $2 \mathrm{H}$, $\left.\mathrm{CH}_{2}, J=6,94 \mathrm{~Hz}\right) ; 0,99$ (t, $3 \mathrm{H}, \mathrm{CH}_{3}, J=6,94 \mathrm{~Hz}$ ).
RMN ${ }^{13} \mathbf{C}: \delta 161,80\left(\mathrm{C}_{9}\right) ; 150,67\left(\mathrm{C}_{6}\right) ; 147,04\left(\mathrm{C}_{2}\right) ; 140,50$ $\left(\mathrm{C}_{13}\right) ; 130,60\left(\mathrm{C}_{5}\right) ; 129,80\left(\mathrm{C}_{10}\right) ; 129,41\left(\mathrm{C}_{12} \mathrm{e} \mathrm{C}_{14}\right) ; 124,63$ $\left(\mathrm{C}_{11}\right.$ e $\left.\mathrm{C}_{15}\right) ; 124,58\left(\mathrm{C}_{4}\right) ; 114,25\left(\mathrm{C}_{3}\right) ; 69,28\left(\mathrm{CH}_{2}\right) ; 21,95$ $\left(\mathrm{CH}_{2}\right) ; 10,35\left(\mathrm{CH}_{3}\right)$.

AE: C: $52,08 \%\left(53,04 \%{ }_{\text {calc. }}\right)$; H: 4,60\% $\left(4,54 \%_{\text {calc. }}\right) ; \mathrm{N}$ : $12,31 \%\left(12,60 \%_{\text {calc. }}\right)$.

\section{5-nitro-2-tiofilideno-4-butoxibenzidrazida (9)}

$\left(\mathrm{C}_{16} \mathrm{H}_{17} \mathrm{O}_{4} \mathrm{~N}_{3} \mathrm{~S}\right)$ Sólido amorfo amarelo escuro. Rendimento: $97 \%$; F.f. $200,5-201,6^{\circ} \mathrm{C}$

IV (KBr): v $\left(\mathrm{cm}^{-1}\right) 3360\left(\mathrm{v}_{\mathrm{N}-\mathrm{H}}\right) ; 3075\left(\mathrm{v}_{\mathrm{C}-\mathrm{H}}\right) ; 1643\left(\mathrm{v}_{\mathrm{C}=\mathrm{O}}\right)$; 1607 e $1507\left(\mathrm{v}_{\mathrm{C}=\mathrm{C}}\right) ; 1570\left(\delta_{\mathrm{N}-\mathrm{H}}\right) ; 1529\left(\mathrm{v}_{\mathrm{N}=\mathrm{O} \text { ass. }}\right) ; 1466$ $\left(\delta_{\mathrm{CH} 2}\right) ; 1384\left(\delta_{\mathrm{CH} 3}\right) ; 1339\left(v_{\mathrm{N}=\mathrm{O} s i m}\right) ; 1256\left(\mathrm{v}_{\mathrm{C}-\mathrm{O}}\right) ; 729\left(\delta_{\mathrm{C}-\mathrm{H}}\right) ;$ $679\left(v_{\mathrm{C}-\mathrm{S}}\right)$.

RMN ${ }^{1} \mathbf{H}: \delta 12,08\left(\mathrm{~s}, 1 \mathrm{H}, \mathrm{H}_{8}\right) ; 8,64\left(\mathrm{~s}, 1 \mathrm{H}, \mathrm{H}_{6}\right) ; 8,11(\mathrm{~d}$, $\left.1 \mathrm{H}, \mathrm{H}_{4}, J=4,18 \mathrm{~Hz}\right) ; 7,87$ (d, $2 \mathrm{H}, \mathrm{H}_{11}$ e $_{15}, J=8,39 \mathrm{~Hz}$ ); $7,04\left(\mathrm{~d}, 2 \mathrm{H}, \mathrm{H}_{12}\right.$ e $\left._{14}, J=8,39 \mathrm{~Hz}\right) ; 7,54\left(\mathrm{~d}, 1 \mathrm{H}, \mathrm{H}_{3}, J=\right.$ $4,18 \mathrm{~Hz}$ ); 4,03 (t, 2H, $\mathrm{CH}_{2}, J=6,80 \mathrm{~Hz}$ ); 1,70 (quinteto, $2 \mathrm{H}, \mathrm{CH}_{2}, J=6,80 \mathrm{~Hz}$ ); 1,40 (sexteto, $2 \mathrm{H}, \mathrm{CH}_{2}, J=6,80$ $\mathrm{Hz}) ; 0,92\left(\mathrm{t}, 3 \mathrm{H}, \mathrm{CH}_{3}, J=6,80 \mathrm{~Hz}\right)$.

RMN ${ }^{13} \mathbf{C}: \delta 161,79\left(\mathrm{C}_{9}\right) ; 150,65\left(\mathrm{C}_{6}\right) ; 147,03\left(\mathrm{C}_{2}\right) ; 140,46$ $\left(\mathrm{C}_{13}\right) ; 130,58\left(\mathrm{C}_{5}\right) ; 129,76\left(\mathrm{C}_{4}\right) ; 129,56\left(\mathrm{C}_{10}\right) ; 129,40$ $\left(\mathrm{C}_{12}\right.$ e C $\left._{14}\right) ; 124,62\left(\mathrm{C}_{11}\right.$ e $\left.\mathrm{C}_{15}\right) ; 114,24\left(\mathrm{C}_{3}\right) ; 67,51\left(\mathrm{CH}_{2}\right)$; 30,61 $\left(\mathrm{CH}_{2}\right) ; 18,69\left(\mathrm{CH}_{2}\right) ; 13,69\left(\mathrm{CH}_{3}\right)$.

AE: C: $56,09 \%\left(55,32 \%_{\text {calc }}\right) ; \mathrm{H}: 5,16 \%\left(4,93 \%_{\text {calc. }}\right)$; N: $11,57 \%\left(11,50 \%_{\text {calc. }}\right)$.

\section{5-nitro-2-tiofilideno-4-butilaminobenzidrazida (10)}

$\left(\mathrm{C}_{16} \mathrm{H}_{18} \mathrm{O}_{3} \mathrm{~N}_{3} \mathrm{~S}\right)$ Sólido amorfo vermelho escuro. Rendimento: $93 \%$; F.f.: $249,1-250,9^{\circ} \mathrm{C}$

IV (KBr): v $\left(\mathrm{cm}^{-1}\right) 3350\left(\mathrm{v}_{\mathrm{N}-\mathrm{H}}\right) ; 3020\left(\mathrm{v}_{\mathrm{C}-\mathrm{H}}\right) ; 1657\left(\mathrm{v}_{\mathrm{C}=\mathrm{O}}\right)$; 1598 e $1474\left(\mathrm{v}_{\mathrm{C}=\mathrm{C}}\right) ; 1571\left(\delta_{\mathrm{N}-\mathrm{H}}\right) ; 1542\left(\mathrm{v}_{\mathrm{N}=\mathrm{O} \text { ass. }}\right) ; 1453$ $\left(\delta_{\mathrm{CH} 2}\right) ; 1373\left(\delta_{\mathrm{CH} 3}\right) ; 1340\left(v_{\mathrm{N}=\mathrm{O} \text { sim. }}\right) ; 729\left(\delta_{\mathrm{C}-\mathrm{H}}\right) ; 645\left(\mathrm{v}_{\mathrm{C}-\mathrm{S}}\right)$. RMN ${ }^{1} \mathrm{H}: \delta 11,86\left(\mathrm{~s}, 1 \mathrm{H}, \mathrm{H}_{8}\right) ; 8,63\left(\mathrm{~s}, 1 \mathrm{H}, \mathrm{H}_{6}\right) ; 8,11(\mathrm{~d}$, $\left.1 \mathrm{H}, \mathrm{H}_{4}, J=4,35 \mathrm{~Hz}\right) ; 7,72$ (d, 2H, $\mathrm{H}_{11}$ e $\mathrm{H}_{15}, J=7,50 \mathrm{~Hz}$ ); $6,60\left(\mathrm{~d}, 2 \mathrm{H}, \mathrm{H}_{12}\right.$ e $\left._{14}, J=7,50 \mathrm{~Hz}\right) ; 7,51\left(\mathrm{~d}, 1 \mathrm{H}, \mathrm{H}_{3}, J=\right.$ $4,35 \mathrm{~Hz}$ ); 6,41 (t, 1H, NH, $J=5,22 \mathrm{~Hz}$ ), 3,07 (duplo dupleto, $2 \mathrm{H}, \mathrm{CH}_{2}, J=6,91 \mathrm{~Hz}, J^{\prime}=5,22 \mathrm{~Hz}$ ); 1,54 (quinteto, $2 \mathrm{H}, \mathrm{CH}_{2}, J=6,91 \mathrm{~Hz}$ ); 1,39 (sexteto, $2 \mathrm{H}, \mathrm{CH}_{2}, J=$ $6,91 \mathrm{~Hz}) ; 0,91$ (t, 3H, $\left.\mathrm{CH}_{3}, J=6,91 \mathrm{~Hz}\right)$.

RMN ${ }^{13} \mathbf{C}: \delta 164,18\left(\mathrm{C}_{9}\right) ; 153,18\left(\mathrm{C}_{6}\right) ; 151,16\left(\mathrm{C}_{2}\right) ; 148,47$ $\left(\mathrm{C}_{13}\right) ; 139,86\left(\mathrm{C}_{5}\right) ; 131,43\left(\mathrm{C}_{10}\right) ; 130,52\left(\mathrm{C}_{12} \mathrm{e} \mathrm{C}_{14}\right) ; 129,62$ $\left(\mathrm{C}_{11}\right.$ e C $\left.{ }_{15}\right) ; 126,29\left(\mathrm{C}_{4}\right) ; 119,18\left(\mathrm{C}_{3}\right) ; 42,87\left(\mathrm{CH}_{2}\right) ; 31,50$ $\left(\mathrm{CH}_{2}\right) ; 20,63\left(\mathrm{CH}_{2}\right) ; 14,64\left(\mathrm{CH}_{3}\right)$.

AE: C: $52,85 \%\left(52,74 \%_{\text {calc }}\right) ; \mathrm{H}: 4,69 \%\left(4,98 \%_{\text {calc. }}\right)$; N: $15,47 \%\left(15,37 \%_{\text {calc. }}\right)$.

\section{5-nitro-2-tiofilideno-4-butilbenzidrazida (11)}

$\left(\mathrm{C}_{16} \mathrm{H}_{17} \mathrm{O}_{3} \mathrm{~N}_{3} \mathrm{~S}\right)$ Sólido amorfo amarelo escuro. Rendimento: $98 \%$; F.f.: $175,8-179,2{ }^{\circ} \mathrm{C}$

IV (KBr): v $\left(\mathrm{cm}^{-1}\right) 3250\left(\mathrm{v}_{\mathrm{N}-\mathrm{H}}\right) ; 3110\left(\mathrm{v}_{\mathrm{C}-\mathrm{H}}\right) ; 1652\left(\mathrm{v}_{\mathrm{C}=\mathrm{O}}\right)$; 
1610 e $1490\left(\mathrm{v}_{\mathrm{C}=\mathrm{C}}\right) ; 1557\left(\delta_{\mathrm{N}-\mathrm{H}}\right) ; 1534\left(\mathrm{v}_{\mathrm{N}=\mathrm{O} \text { ass }}\right) ; 1465$ $\left(\delta_{\mathrm{CH} 2}\right) ; 1393\left(\delta_{\mathrm{CH} 3}\right) ; 1339\left(\mathrm{v}_{\mathrm{N}=\mathrm{O} \text { sim } \mathrm{H}}\right) ; 729\left(\delta_{\mathrm{C}-\mathrm{H}}\right) ; 656\left(\mathrm{v}_{\mathrm{C}-\mathrm{S}}\right)$. RMN ${ }^{1} \mathbf{H}: \delta 12,18\left(\mathrm{~s}, 1 \mathrm{H}, \mathrm{H}_{8}\right) ; 8,67\left(\mathrm{~s}, 1 \mathrm{H}, \mathrm{H}_{6}\right) ; 8,14(\mathrm{~d}$, $\left.1 \mathrm{H}, \mathrm{H}_{4}, J=4,27 \mathrm{~Hz}\right) ; 7,83$ (d, 2H, $\mathrm{H}_{11}$ e $\mathrm{H}_{15}, J=7,90 \mathrm{~Hz}$ ); $7,36\left(\mathrm{~d}, 2 \mathrm{H}, \mathrm{H}_{12} \mathrm{e} \mathrm{H}_{14}, J=7,90 \mathrm{~Hz}\right) ; 7,58\left(\mathrm{~d}, 1 \mathrm{H}, \mathrm{H}_{3}, J=\right.$ $4,27 \mathrm{~Hz}$ ); 2,65 (t, 2H, $\mathrm{CH}_{2}, J=7,63 \mathrm{~Hz}$ ); 1,57 (quinteto, $2 \mathrm{H}, \mathrm{CH}_{2}, J=7,63 \mathrm{~Hz}$ ); 1,32 (sexteto, $2 \mathrm{H}, \mathrm{CH}_{2}, J=7,63$ $\mathrm{Hz}), 0,90$ (t, 3H, $\left.\mathrm{CH}_{3}, J=7,63 \mathrm{~Hz}\right)$.

$\mathbf{R M N}{ }^{13} \mathbf{C}: \delta 163,03\left(\mathrm{C}_{9}\right) ; 151,61\left(\mathrm{C}_{6}\right) ; 147,92\left(\mathrm{C}_{2}\right) ; 147,73$ $\left(\mathrm{C}_{13}\right) ; 141,71\left(\mathrm{C}_{5}\right) ; 131,41\left(\mathrm{C}_{10}\right) ; 131,12\left(\mathrm{C}_{12} \mathrm{e} \mathrm{C}_{14}\right) ; 130,43$ $\left(\mathrm{C}_{11}\right.$ e $\left.\mathrm{C}_{15}\right) ; 129,33\left(\mathrm{C}_{4}\right) ; 128,67\left(\mathrm{C}_{3}\right) ; 35,56\left(\mathrm{CH}_{2}\right) ; 33,69$ $\left(\mathrm{CH}_{2}\right) ; 22,59\left(\mathrm{CH}_{2}\right) ; 14,61\left(\mathrm{CH}_{3}\right)$.

AE: C: $58,32 \%\left(57,99 \%_{\text {calc. }}\right) ; \mathrm{H}: 5,30 \%\left(5,17 \%_{\text {calc. }}\right)$; N: $12,77 \%\left(12,07 \%_{\text {calc. }}\right)$.

\section{5-nitro-2-tiofilideno-4-etilbenzidrazida (12)}

$\left(\mathrm{C}_{14} \mathrm{H}_{13} \mathrm{O}_{3} \mathrm{~N}_{3} \mathrm{~S}\right)$ Sólido amorfo amarelo escuro. Rendimento: $94 \%$; F.f.: $207,2-208,5^{\circ} \mathrm{C}$

IV (KBr): $v\left(\mathrm{~cm}^{-1}\right) 3310\left(\mathrm{v}_{\mathrm{N}-\mathrm{H}}\right) ; 3105\left(\mathrm{v}_{\mathrm{C}-\mathrm{H}}\right) ; 1649\left(\mathrm{v}_{\mathrm{C}=\mathrm{O}}\right)$; 1611 e $1503\left(v_{\mathrm{C}=\mathrm{C}}\right) ; 1567\left(\delta_{\mathrm{N}-\mathrm{H}}\right) ; 1544\left(\mathrm{v}_{\mathrm{N}=\mathrm{O} \text { ass. }}\right)$; $14652\left(\delta_{\mathrm{CH} 2}\right) ; 1376\left(\delta_{\mathrm{CH} 3}\right) ; 1342\left(\mathrm{v}_{\mathrm{N}=\mathrm{O} \text { sim }}\right) ; 730\left(\delta_{\mathrm{C}-\mathrm{H}}\right) ; 660$ $\left(v_{\mathrm{C}-\mathrm{S}}\right)$.

RMN ${ }^{1} \mathbf{H}: \delta 12,19\left(\mathrm{~s}, 1 \mathrm{H}, \mathrm{H}_{8}\right) ; 8,68\left(\mathrm{~s}, 1 \mathrm{H}, \mathrm{H}_{6}\right) ; 8,13$ (d, $\left.1 \mathrm{H}, \mathrm{H}_{4}, J=4,30 \mathrm{~Hz}\right) ; 7,84$ (d, 2H, $\mathrm{H}_{11}$ e $\mathrm{H}_{15}, J=7,80 \mathrm{~Hz}$ ); 7,38 (d, 2H, $\mathrm{H}_{12}$ e $\left._{14}, J=7,80 \mathrm{~Hz}\right) ; 7,58\left(\mathrm{~d}, 1 \mathrm{H}, \mathrm{H}_{3}, J=\right.$ $4,30 \mathrm{~Hz}$ ); 2,50 (quarteto, $2 \mathrm{H}, \mathrm{CH}_{2}, J=7,54 \mathrm{~Hz}$ ); 1,21 (t, $\left.3 \mathrm{H}, \mathrm{CH}_{3}, J=7,54 \mathrm{~Hz}\right)$.

RMN ${ }^{13} \mathbf{C}: \delta 164,09\left(\mathrm{C}_{9}\right) ; 151,61\left(\mathrm{C}_{6}\right) ; 149,30\left(\mathrm{C}_{2}\right) ; 147,72$ $\left(\mathrm{C}_{13}\right) ; 141,76\left(\mathrm{C}_{5}\right) ; 131,42\left(\mathrm{C}_{10}\right) ; 131,11\left(\mathrm{C}_{12} \mathrm{e} \mathrm{C}_{14}\right) ; 130,44$ $\left(\mathrm{C}_{11}\right.$ e $\left._{15}\right) ; 128,82\left(\mathrm{C}_{4}\right) ; 126,30\left(\mathrm{C}_{3}\right) ; 28,97\left(\mathrm{CH}_{2}\right) ; 16,19$ $\left(\mathrm{CH}_{3}\right)$.

AE: C: $53,01 \%\left(52,33 \%_{\text {calc }}\right)$; H: 4,14\% $\left(4,08 \%_{\text {calc }}\right) ; \mathrm{N}$ : $13,95 \%\left(13,08 \%_{\text {calc. }}\right)$.

\section{5-nitro-2-tiofilideno-4-vinilbenzidrazida (13)}

$\left(\mathrm{C}_{14} \mathrm{H}_{11} \mathrm{O}_{3} \mathrm{~N}_{3} \mathrm{~S}\right)$ Sólido amorfo amarelo escuro. Rendimento: $90 \%$; F.f.: $202,1-204{ }^{\circ} \mathrm{C}$

IV (KBr): v $\left(\mathrm{cm}^{-1}\right) 3300\left(\mathrm{v}_{\mathrm{N}-\mathrm{H}}\right) ; 3105\left(\mathrm{v}_{\mathrm{C}-\mathrm{H}}\right) ; 1658\left(\mathrm{v}_{\mathrm{C}=\mathrm{O}}\right)$; 1608 e $1496\left(v_{\mathrm{C}=\mathrm{C}}\right) ; 1573\left(\delta_{\mathrm{N}-\mathrm{H}}\right) ; 1529\left(\mathrm{v}_{\mathrm{N}=\mathrm{O} \text { ass. }}\right) ; 1328$ $\left(\mathrm{v}_{\mathrm{N}=\mathrm{O} \text { sim. }}\right) ; 1003$ e $903\left(\delta_{\mathrm{C}-\mathrm{H}, \text { vinil }}\right) ; 729\left(\delta_{\mathrm{C}-\mathrm{H}}\right) ; 655\left(\mathrm{v}_{\mathrm{C}-\mathrm{S}}\right)$.

RMN $^{1} \mathbf{H}: \delta 12,18\left(\mathrm{~s}, 1 \mathrm{H}, \mathrm{H}_{8}\right) ; 8,65\left(\mathrm{~s}, 1 \mathrm{H}, \mathrm{H}_{6}\right) ; 8,10(\mathrm{~d}$, $\left.1 \mathrm{H}, \mathrm{H}_{4}, J=4,24 \mathrm{~Hz}\right) ; 7,85$ (d, 2H, $\mathrm{H}_{11} \mathrm{e} \mathrm{H}_{15}, J=7,63 \mathrm{~Hz}$ ); 7,60 (d, 2H, $\left.\mathrm{H}_{12} \mathrm{e} \mathrm{H}_{14}, J=7,64 \mathrm{~Hz}\right) ; 7,54\left(\mathrm{~d}, 1 \mathrm{H}, \mathrm{H}_{3}, J=\right.$ $4,24 \mathrm{~Hz}) ; 6,77\left(\mathrm{dd}, 1 \mathrm{H}, \mathrm{H}_{\mathrm{A}}, J_{A B}=10,95 \mathrm{~Hz}, \mathrm{~J}_{\mathrm{AC}}=6,70\right.$ $\mathrm{Hz}) ; 5,91\left(\mathrm{~d}, 1 \mathrm{H}, \mathrm{H}_{\mathrm{B}}, J_{B C}=1,70 \mathrm{~Hz}\right) ; 5,37\left(\mathrm{~d}, 1 \mathrm{H}, \mathrm{H}_{\mathrm{C}}, J_{C B}\right.$ $=1,70 \mathrm{~Hz}$ ).

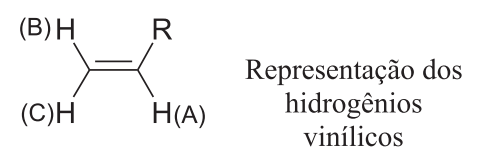

RMN ${ }^{13} \mathbf{C}: \delta 161,62\left(\mathrm{C}_{9}\right) ; 147,63\left(\mathrm{C}_{6}\right) ; 142,01\left(\mathrm{C}_{2}\right) ; 141,59$ $\left(\mathrm{C}_{13}\right) ; 136,66\left(\mathrm{C}_{5}\right) ; 136,01(\mathrm{CH}) ; 131,42\left(\mathrm{C}_{10}\right) ; 130,55\left(\mathrm{C}_{12}\right.$ $\left.\mathrm{e} \mathrm{C}_{14}\right) ; 129,03\left(\mathrm{C}_{11}\right.$ e $\left._{15}\right) ; 127,08\left(\mathrm{C}_{4}\right) ; 126,29\left(\mathrm{C}_{3}\right), 117,76$ $\left(\mathrm{CH}_{2}\right)$.

AE: C: $52,87 \%\left(52,66 \%_{\text {calc }}\right) ; \mathrm{H}: 3,60 \%\left(3,47 \%_{\text {calc. }}\right)$; N: $13,31 \%\left(13,16 \%_{\text {calc. }}\right)$.

\section{5-nitro-2-tiofilideno-4-acetilbenzidrazida (14)}

$\left(\mathrm{C}_{12} \mathrm{H}_{11} \mathrm{O}_{4} \mathrm{~N}_{3} \mathrm{~S}\right)$ Sólido amorfo amarelo escuro. Rendimento: $90 \%$; F.f.: $228,1-233{ }^{\circ} \mathrm{C}$

IV (KBr): v $\left(\mathrm{cm}^{-1}\right) 3355\left(\mathrm{v}_{\mathrm{N}-\mathrm{H}}\right) ; 3095\left(\mathrm{v}_{\mathrm{C}-\mathrm{H}}\right) ; 1676\left(\mathrm{v}_{\mathrm{C}=\mathrm{O}}\right)$; 1607 e $1494\left(\mathrm{v}_{\mathrm{C}=\mathrm{C}}\right) ; 1584\left(\delta_{\mathrm{N}-\mathrm{H}}\right) ; 1522\left(\mathrm{v}_{\mathrm{N}=\mathrm{O} \text { ass. }}\right) ; 1329$ $\left(v_{\mathrm{N}=\mathrm{O} \operatorname{sim}}\right) ; 727\left(\delta_{\mathrm{C}-\mathrm{H}}\right) ; 672\left(\mathrm{v}_{\mathrm{C}-\mathrm{S}}\right)$.

$\mathbf{R M N}^{1} \mathbf{H}: \delta 12,29\left(\mathrm{~s}, 1 \mathrm{H}, \mathrm{H}_{8}\right) ; 8,60\left(\mathrm{~s}, 1 \mathrm{H}, \mathrm{H}_{6}\right) ; 7,92(\mathrm{~d}$, $\left.1 \mathrm{H}, \mathrm{H}_{4}, J=4,20 \mathrm{~Hz}\right) ; 7,76-7,67$ (m, 4H, $\mathrm{H}_{11}, \mathrm{H}_{12}, \mathrm{H}_{14} \mathrm{e} \mathrm{H}_{15}$ ); $3,26\left(\mathrm{~s}, 3 \mathrm{H}, \mathrm{CH}_{3}\right)$.

RMN ${ }^{13} \mathbf{C}: \delta 163,45\left(\mathrm{C}_{9}\right) ; 158,20(\mathrm{C}=\mathrm{O}) ; 153,18\left(\mathrm{C}_{6}\right)$; $147,34\left(\mathrm{C}_{2}\right) ; 144,63\left(\mathrm{C}_{13}\right) ; 142,61\left(\mathrm{C}_{5}\right) ; 135,44\left(\mathrm{C}_{10}\right)$; $131,34\left(\mathrm{C}_{12}\right.$ e C $\left._{14}\right) ; 130,81\left(\mathrm{C}_{11}\right.$ e $\left.\mathrm{C}_{15}\right) ; 129,92\left(\mathrm{C}_{4}\right) ; 128,93$ $\left(\mathrm{C}_{3}\right) ; 27,86\left(\mathrm{CH}_{3}\right)$.

AE: C: $53,97 \%\left(52,99 \%_{\text {calc }}\right) ; \mathrm{H}: 3,83 \%\left(3,49 \%_{\text {calc. }}\right)$; N: $14,12 \%\left(13,24 \%_{\text {calc. }}\right)$.

\section{Ensaios microbiológicos}

Determinou-se a concentração inibitória mínima, CIM, frente à cepa padrão de Staphylococcus aureus (ATCC 25923) dos quatorze compostos obtidos (1 a 14) seguindo metodologia de macrodiluição sucessiva adaptada por Tavares e colaboradores (Tavares, Penna, Amaral, 1997). A cepa em questão foi gentilmente cedida pela Profa. Dra. Thereza Christina Vessoni-Penna do Departamento de Tecnologia Bioquímico-Farmacêutica da Faculdade de Ciências Farmacêuticas da Universidade de São Paulo.

Para a avaliação precisa da eficácia dos compostos sintetizados frente à cepa multi-resistente de Staphylococcus aureus (3SP/R33) adotou-se a mesma técnica utilizada na realização do ensaio microbiológico frente à cepa padrão.

A cepa multi-resistente (3SP/R33) utilizada neste estudo foi coletada de pacientes hospitalizados do Estado de São Paulo e encontra-se estocada no Laboratório Referência Nacional em Fagotipagem de Staphylococcus aureus no Departamento de Análises Clínicas e Toxicológicas da FCFUSP, sob coordenação da Profa. Dra. Elsa Masae Mamizuka. A escolha desta cepa se deve ao fato de ela apresentar resistência a dezenove antibióticos utilizados na terapêutica atual para o tratamento de infecções causadas por este gênero de bactéria, com sensibilidade apenas à vancomicina (Oliveira et al., 2001) (Tabela I). 
TABELA I - Espectro de multi-resistência da cepa 3SP/R33 de Staphylococcus aureus utilizada na avaliação da atividade antimicrobiana de 5-nitro-2-tiofilidenobenzidrazidas *

\begin{tabular}{lclc}
\hline ANTIMICROBIANO & RESISTÊNCIA & ANTIMICROBIANO & RESISTÊNCIA \\
\hline Amoxicilina/Ácido clavulânico & $(+)$ & Gentamicina & $(+)$ \\
Ampicilina & $(+)$ & Imipenem & $(+)$ \\
Cefazolina & $(+)$ & Nitrofurantoína & $(+)$ \\
Cefotaxima & $(+)$ & Norfloxacino & $(+)$ \\
Cefalotina & $(+)$ & Oxacilina & $(+)$ \\
Ciprofloxacino & $(+)$ & Penicilina & $(+)$ \\
Clindamicina & $(+)$ & Rifampicina & $(+)$ \\
Eritromicina & $(+)$ & Trimetoprima/Sulfametoxazol & $(+)$ \\
& Vancomicina & $(-)$ & \\
\hline
\end{tabular}

Nota: $(+)=$ ocorrência de resistência; $(-)$ = não ocorrência de resistência

Microrganismos. Staphylococcus aureus: cepas ATCC 25923 (padrão) e 3SP/R33 (multi-resistente) (Oliveira et al., 2001).

Concentração inibitória mínima. A determinação da concentração inibitória mínima, CIM, dos compostos obtidos envolveu duas fases. Na primeira etapa, fase I, determinou-se de forma quantitativa a atividade antimicrobiana dos compostos obtidos, utilizando método clássico de macrodiluição sucessiva em tubos (Tavares, 1993; Collins, 1995). Na segunda etapa, fase II, utilizou-se metodologia adaptada por Tavares e colaboradores (Tavares, Penna, Amaral, 1997) com o propósito de intensificar a sensibilidade do ensaio.

Concentração bactericida mínima. A partir dos resultados obtidos na determinação da concentração inibitória mínima, CIM, por aplicação do método de macrodiluição sucessiva, foram selecionados os tubos que continham soluções em que não havia se detectado crescimento do microrganismo teste e realizou-se a determinação da concentração bactericida mínima, CBM, seguindo metodologia descrita por Kirby-Bauer (Bauer et al., 1966). As leituras de inibição/crescimento microbiano foram realizadas após 24 horas de incubação a $35^{\circ} \mathrm{C}$. Considerou-se como compostos com atividade bactericida aqueles em que se detectou o crescimento de até 10 unidades formadoras de colônia (UFC) (Bauer et al., 1966), ressaltando que acima deste valor foi atribuída apenas atividade bacteriostática aos compostos testados.

Inóculo. Procedeu-se à lavagem das colônias de três tubos com culturas de 24 horas de Staphylococcus aureus em PCA inclinado, com porções equivalentes a $5,0 \mathrm{~mL}$ de solução salina a $0,85 \%$ para cada tubo. Transferiram-se as suspensões obtidas para frasco contendo pérolas de vidro e barra magnética. Manteve-se a suspensão sob agitação constante por 30 minutos para homogeneização do meio. Transferiu-se 1,0 mL desta suspensão para frasco contendo $99,0 \mathrm{~mL}$ de solução salina, pérolas de vidro e barra magnética, obtendose suspensão de $1,0 \times 10^{-2} \mathrm{UFC} / \mathrm{mL}$ em relação à suspensão inicial. Manteve-se esta segunda suspensão sob agitação constante por 15 minutos. Repetiu-se este mesmo procedimento para a suspensão seguinte, obtendo-se concentração equivalente a $1,0 \times 10^{-4} \mathrm{UFC} / \mathrm{mL}$. Por fim, transferiu-se $1,0 \mathrm{~mL}$ da suspensão anterior de $1,0 \times 10^{-4} \mathrm{UFC} / \mathrm{mL}$ para frasco contendo 99,0 mL de TSB (Tryptic Soy Broth, Merck), pérolas de vidro e barra magnética, gerando inóculo de 0,5 na escala Mc Farland, utilizado na realização do ensaio.

Amostras. Para cada substância a ser testada, prepararam-se $10,0 \mathrm{~mL}$ de solução do antimicrobiano com concentração equivalente a $1,8 \times 10^{-3} \mathrm{M}$ em DMSO, para compostos mais hidrossolúveis, e, alternativamente, em DMSO e álcool etílico (co-solvente), na proporção de 1:1 (v/v), para os compostos mais lipossolúveis. Foram transferidos 5,0 mL desta solução para frasco contendo 5,0 mL de TSB, de forma a originar solução de concentração equivalente a $0,9 \times 10^{-3} \mathrm{M}$, posteriormente empregada na execução do ensaio.

\section{RESULTADOS E DISCUSSÃO}

\section{Síntese das 5-nitro-2-tiofilidenobenzidrazidas}

As 5-nitro-2-tiofilidenobenzidrazidas foram obtidas em três etapas, a saber: obtenção de benzoatos de metila a partir de ácidos benzóicos, obtenção de benzidrazidas a partir de benzoatos de metila e obtenção de bases de Schiff a partir de benzidrazidas e do 5-nitro-2-tiofenocarboxaldeído (Figura 2). 


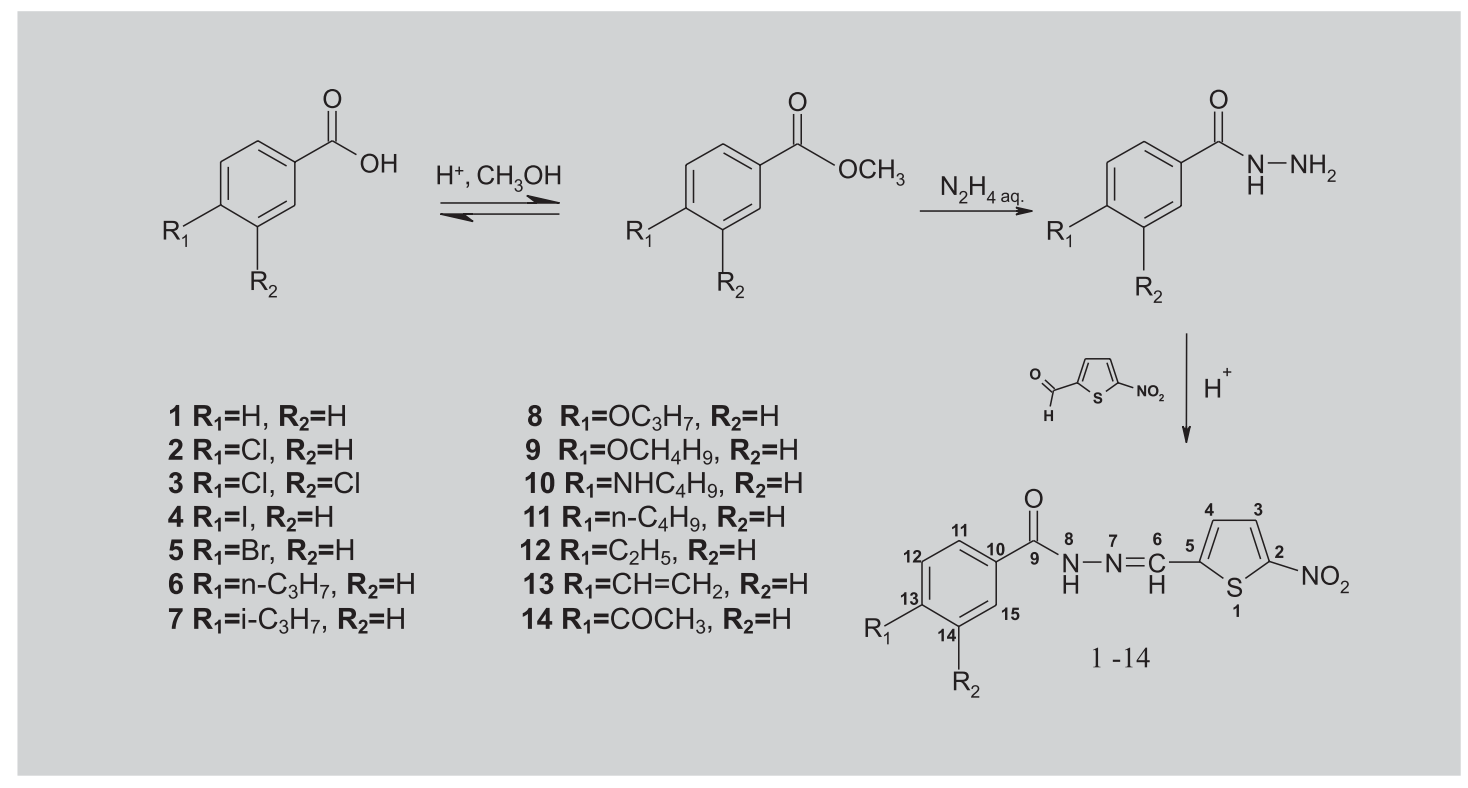

FIGURA 2 - Rota de síntese para a obtenção das 5-nitro-2-tiofilidenobenzidrazidas.

A síntese dos derivados em estudo se mostrou simples, prática e com rendimentos satisfatórios, fator essencial em uma abordagem de química medicinal na qual é primordial a facilidade de síntese de grande número de análogos. A esterificação clássica de Fisher (Carey, 2000; Solomons, 2000), uma reação de condensação de caráter reversível, apresentou rendimentos satisfatórios, em torno de $90 \%$. Observou-se na reação de amonólise (Carey, 2000; Solomons, 2000), segunda etapa da síntese total, rendimentos consideravelmente menores devido, primeiramente, às diferentes reatividades dos ésteres, por influência dos grupos substituintes, como também pela dificuldade de cristalização e alta solubilidade em água dos sólidos obtidos. A formação de bases de Schiff, última etapa da rota sintética utilizada foi realizada com sucesso (rendimentos de 95\%). Trata-se de uma reação de adição nucleofílica (Carey, 2000; Solomons, 2000) catalisada por ácido. Inicialmente, em decorrência do $\mathrm{pH}$ do meio, ocorre a protonação do oxigênio carbonílico do grupamento aldeído tornando-o suscetível ao ataque nucleofílico. A reação se completa com o ataque do grupo amina primária da benzidrazida ao centro deficiente em elétrons e subsequente liberação de água. Nesta reação, o meio deve estar suficientemente ácido para que ocorra a protonação de fração apreciável do composto carbonílico, sem, no entanto, permitir decréscimo acentuado da concentração do composto nitrogenado livre. Define-se, portanto, a basicidade da amina e a reatividade da substância carbonílica como as principais condições envolvidas na determinação da velocidade desta reação (Carey, 2000; Solomons, 2000).

\section{Avaliação da atividade antimicrobiana dos compostos obtidos}

\section{Staphylococcus aureus: cepa ATCC 25923}

Testes de toxicidade de solvente (DMSO) e cosolvente (álcool etílico) mostraram que o álcool etílico isolado, nas proporções que foram utilizadas nos ensaios, não causou qualquer influência no crescimento do microrganismo, já a mistura álcool etílico/DMSO $(1: 1, \mathrm{v} / \mathrm{v})$ apresentou interferência sobre o crescimento microbiano em concentrações acima de $25 \%$, confirmando os estudos de toxicidade do DMSO isolado, previamente realizados por Tavares e colaboradores (Tavares, Penna, Amaral, 1997). Apresentam-se, na tabela II, as concentrações inibitórias mínimas, CIM, das 5-nitro-2-tiofilideno benzidrazidas frente à cepa ATCC 25923 de Staphylococcus aureus.

Comparando a atividade antimicrobiana dos compostos sintetizados em relação à nifuroxazida e a nitrofurantoína frente à cepa padrão (tabela II) observou-se que todos os derivados mostraram-se mais ativos que a nitrofurantoína, enquanto que os compostos $p-\mathrm{Cl}(2), m, p-\mathrm{Cl}_{2}$ (3), $p$ - $\mathrm{Br}$ (5) e $p$ - $\mathrm{COCH}_{3}$ (14) mostraram-se consideravelmente mais ativos que a nifuroxazida. Entre os compostos sintetizados, identificados e testados frente à cepa ATCC 25923 de Staphylococcus aureus constatou-se que a 5-nitro-2tiofilideno-4-acetilbenzidrazida (14) é o composto mais ativo $(\mathrm{CIM}=0,14 \mu \mathrm{g} / \mathrm{mL})$, enquanto que a 5-nitro-2tiofilideno-4-butilbenzidrazida (11) é o composto de mais baixa atividade $(\mathrm{CIM}=13,50 \mu \mathrm{g} / \mathrm{mL})$. Ressalta-se ainda, que todos os compostos testados apresentaram valores de concentração inibitória mínima em região com concentração de 
TABELA II - Concentração inibitória mínima, CIM, de 5-nitro-2-tiofilideno benzidrazidas frente à cepa ATCC 25923 de Staphylococcus aureus ${ }^{\mathrm{I}}$

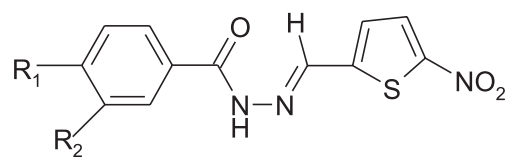

\begin{tabular}{|c|c|c|c|c|c|c|}
\hline \multirow[b]{2}{*}{$\mathrm{N}^{\circ}$} & \multirow[b]{2}{*}{$\mathrm{R}_{1}$} & \multirow[b]{2}{*}{$\mathrm{R}_{2}$} & \multicolumn{2}{|c|}{$\mathrm{CIM}(\mu \mathrm{g} / \mathrm{mL})^{*}$} & \multirow{2}{*}{$\begin{array}{l}\text { CIM } \\
\mu M\end{array}$} & \multirow{2}{*}{$\begin{array}{c}\text { Potência } \\
\text { Log }(1 / \mathrm{CIM})\end{array}$} \\
\hline & & & Fase I & Fase II & & \\
\hline 1 & $\mathrm{H}$ & $\mathrm{H}$ & $7,81-3,90$ & $\leq 4,59$ & $\leq 16,67$ & $\leq-1,22$ \\
\hline 2 & $\mathrm{Cl}$ & $\mathrm{H}$ & $2,18-1,09$ & $\leq 1,71$ & $\leq 5,52$ & $\leq-0,74$ \\
\hline 3 & $\mathrm{Cl}$ & $\mathrm{Cl}$ & $0,63-1,27$ & $\leq 0,76$ & $\leq 2,21$ & $\leq-0,34$ \\
\hline 4 & I & $\mathrm{H}$ & $11,10-5,55$ & $\leq 5,62$ & $\leq 14,01$ & $\leq-1,15$ \\
\hline 5 & $\mathrm{Br}$ & $\mathrm{H}$ & $1,25-0,63$ & $\leq 0,75$ & $\leq 2,12$ & $\leq-0,32$ \\
\hline 6 & $\mathrm{n}-\mathrm{C}_{3} \mathrm{H}_{7}$ & $\mathrm{H}$ & $14,50-7,25$ & $\leq 11,60$ & $\leq 36,55$ & $\leq-1,56$ \\
\hline 7 & $\mathrm{i}-\mathrm{C}_{3} \mathrm{H}_{7}$ & $\mathrm{H}$ & $10,04-5,02$ & $\leq 9,06$ & $\leq 28,55$ & $\leq-1,46$ \\
\hline 8 & $\mathrm{OC}_{3} \mathrm{H}_{7} * *$ & $\mathrm{H}$ & - & $\leq 8,10$ & $\leq 24,29$ & $\leq-1,38$ \\
\hline 9 & $\mathrm{OC}_{4} \mathrm{H}_{9}$ & $\mathrm{H}$ & $20,62-10,31$ & $\leq 12,30$ & $\leq 35,41$ & $\leq-1,55$ \\
\hline 10 & $\mathrm{NHC}_{4}^{4} \mathrm{H}_{9}$ & $\mathrm{H}$ & $12,45-6,22$ & $\leq 7,75$ & $\leq 22,37$ & $\leq-1,35$ \\
\hline 11 & $\mathrm{n}-\mathrm{C}_{4} \mathrm{H}_{9}^{9}$ & $\mathrm{H}$ & $25,40-12,70$ & $\leq 13,50$ & $\leq 40,74$ & $\leq-1,61$ \\
\hline 12 & $\mathrm{C}_{2} \mathrm{H}_{5}^{9}$ & $\mathrm{H}$ & $11,60-5,80$ & $\leq 6,75$ & $\leq 22,25$ & $\leq-1,35$ \\
\hline 13 & $\mathrm{CH}=\stackrel{2}{=} \mathrm{CH}_{2}$ & $\mathrm{H}$ & $6,75-3,38$ & $\leq 4,72$ & $\leq 15,66$ & $\leq-1,19$ \\
\hline 14 & $\mathrm{COCH}_{3}^{2}$ & $\mathrm{H}$ & $0,22-0,11$ & $\leq 0,14$ & $\leq 0,44$ & $\leq 0,36$ \\
\hline \multicolumn{3}{|c|}{ nitrofurantoína } & \multicolumn{2}{|c|}{$16,00^{\mathrm{II}}$} & \multicolumn{2}{|r|}{ - } \\
\hline \multicolumn{3}{|c|}{ nifuroxazida } & \multicolumn{2}{|c|}{$3,60^{\mathrm{III}}$} & \multicolumn{2}{|r|}{ - } \\
\hline
\end{tabular}

Notas: * Leituras de inibição/crescimento realizadas após 18 horas de incubação a $35^{\circ} \mathrm{C} ;{ }^{*}$ CIM não determinada na fase I devido à insolubilidade do derivado nas concentrações requeridas no ensaio; ${ }^{\mathrm{I}}$ Masunari et al., 2003; ${ }^{\mathrm{II}} \mathrm{Jones}$ et al., 1993; III Tavares, Penna, Amaral, 1997.

DMSO muito abaixo de seu limite crítico, permitindo atribuir a inibição do crescimento microbiano apenas à atividade antibacteriana inerente aos compostos em estudo.

\section{Staphylococcus aureus: cepa 3SP/R33}

Entre os compostos avaliados frente à cepa multiresistente de Staphylococcus aureus (resultados apresentados na tabela III), constatou-se, em concordância com os resultados obtidos frente à cepa padrão, que a 5-nitro2-tiofilideno-4-acetilbenzidrazida (14) se mostrou como o derivado mais ativo $(\mathrm{CIM}=0,22-0,11 \mu \mathrm{g} / \mathrm{mL})$ enquanto que a 5-nitro-2-tiofilideno-4-butilbenzidrazida (11), com $\mathrm{CIM}=25,40-12,70 \mu \mathrm{g} / \mathrm{mL}$, se apresentou como o composto de mais baixa atividade.

O composto 5-nitro-2-tiofilideno-4-butilbenzidrazida (11), com valor de CIM na faixa de 25,40-12,70 $\mu \mathrm{g} / \mathrm{mL}$, não apresentou atividade bactericida mesmo em concentração equivalente a $50,80 \mu \mathrm{g} / \mathrm{mL}$, valor correspondente aos limites de solubilidade impostos pelo ensaio. Em outras palavras, devido à alta hidrofobicidade do composto citado, a concen- tração máxima obtida durante a realização do teste sem que houvesse precipitação da amostra no meio de cultura foi equivalente a 50,80 $\mu \mathrm{g} / \mathrm{mL}$. Observou-se a mesma limitação para os compostos substituídos com $n-\mathrm{C}_{3} \mathrm{H}_{7}(6), i-\mathrm{C}_{3} \mathrm{H}_{7}(7), \mathrm{I}$ (4), $\mathrm{OC}_{4} \mathrm{H}_{9}(11), \mathrm{NHC}_{4} \mathrm{H}_{9}(10), n-\mathrm{C}_{4} \mathrm{H}_{9}(11) \mathrm{e}_{2} \mathrm{H}_{5}$ (12) devido ao elevado caráter lipofílico. A 5-nitro-2-tiofilidenobenzidrazida (1), com CIM = 7,81-3,90 $\mu \mathrm{g} / \mathrm{mL}$, apresentou atividade bactericida em concentração relativamente elevada $(\mathrm{CBM}=125 \mu \mathrm{g} / \mathrm{mL})$ se comparada à atividade bactericida constatada para os compostos $p-\mathrm{Cl}(2)(\mathrm{CBM}=$ $4,37-2,18 \mathrm{mg} / \mathrm{mL}), p-\mathrm{COCH}_{3}(14)(\mathrm{CBM}=0,22-0,11 \mu \mathrm{g} /$ $\mathrm{mL}), p-\mathrm{Br}(5)(\mathrm{CBM}=1,25-0,63 \mu \mathrm{g} / \mathrm{mL})$ e $m, p-\mathrm{Cl}_{2}(3)$ $(\mathrm{CBM}=0,63-1,27 \mu \mathrm{g} / \mathrm{mL})$, nos quais os valores de CBM são o dobro (2 e 14) ou equivalentes (3 e 5) à CIM determinada pelo método de macrodiluição sucessiva.

As informações obtidas experimentalmente (tabela III), sugerem que o derivado não substituído (1) apresenta primordialmente atividade bacteriostática, já que o valor de CBM determinado é muito maior que o de CIM. Por outro lado, os derivados $p-\mathrm{Br}(5), p-\mathrm{Cl}(2)$, 
TABELA III - Concentrações inibitória e bactericida mínimas de 5-nitro-2-tiofilideno benzidrazidas frente à cepa 3SP/ R33* de Staphylococcus aureus ${ }^{\text {I }}$

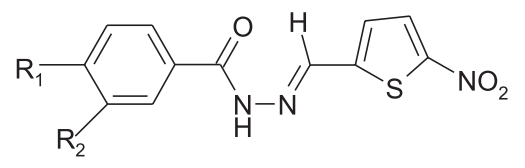

\begin{tabular}{lcccc}
\hline $\mathrm{N}^{\circ}$ & $\mathrm{R}_{1}$ & $\mathrm{R}_{2}$ & $\mathrm{CIM}(\mu \mathrm{g} / \mathrm{mL})$ & $\mathrm{CBM}(\mu \mathrm{g} / \mathrm{mL})$ \\
\hline 1 & $\mathrm{H}$ & $\mathrm{H}$ & $7,81-3,90$ & $\geq 125,00$ \\
2 & $\mathrm{Cl}$ & $\mathrm{H}$ & $2,18-1,09$ & $4,37-2,18$ \\
3 & $\mathrm{Cl}$ & $\mathrm{Cl}$ & $0,63-1,27$ & $0,63-1,27$ \\
4 & $\mathrm{I}$ & $\mathrm{H}$ & $11,10-5,55$ & $>88,80 * *$ \\
5 & $\mathrm{Br}$ & $1,25-0,63$ & $1,25-0,63$ \\
6 & $n-\mathrm{C}_{3} \mathrm{H}_{7}$ & $\mathrm{H}$ & $14,50-7,25$ & $>29,00^{* *}$ \\
7 & $i-\mathrm{C}_{3} \mathrm{H}_{7}$ & $\mathrm{H}$ & $10,04-5,02$ & $>40,16 * *$ \\
8 & $\mathrm{OC}_{3} \mathrm{H}_{7}$ & $\mathrm{H}$ & $20,62-10,31$ & $>41,24 * *$ \\
9 & $\mathrm{OC}_{4} \mathrm{H}_{9}$ & $\mathrm{H}$ & $12,45-6,22$ & $>49,80 * *$ \\
10 & $\mathrm{NHC}_{4} \mathrm{H}_{9}$ & $\mathrm{H}$ & $25,40-12,70$ & $>50,80 * *$ \\
11 & $n-\mathrm{C}_{4} \mathrm{H}_{9}$ & $\mathrm{H}$ & $11,60-5,80$ & $>92,80 * *$ \\
12 & $\mathrm{C}_{2} \mathrm{H}_{5}$ & $\mathrm{H}$ & $6,75-3,38$ & $>54,00 * *$ \\
13 & $\mathrm{CH}_{5}=\mathrm{CH}_{2}$ & $\mathrm{H}$ & $0,22-0,11$ & $0,44-0,22$ \\
14 & $\mathrm{COCH}_{3}$ & $\mathrm{H}$ &
\end{tabular}

${ }^{\mathrm{I}}$ Masunari et al., 2003; * cepa multi-resistente de S.aureus, coletada de pacientes hospitalizados e estocada no Laboratório Referência Nacional em Fagotipagem de S.aureus da FCF/USP; ** compostos que não apresentaram atividade bactericida nas condições de solubilidade permitidas pelo ensaio; *** CIM e CBM não determinadas devido à insolubilidade do composto nas concentrações requeridas para o teste

$m, p-\mathrm{Cl}_{2}(3)$ e $p-\mathrm{COCH}_{3}(14)$, exibiram excelente atividade bacteriostática e exerceram efeito bactericida em concentrações significativamente baixas, mostrando serem os derivados mais potentes entre os compostos estudados neste trabalho.

Ressalta-se que a excelente atividade bactericida constatada para a maioria dos análogos em estudo sinaliza a importância de realização de estudos mais aprofundados desta série de compostos que tem mostrado ser muito promissora na identificação de alternativas viáveis para o tratamento de infecções causadas por Staphylococcus aureus com caráter de multi-resistência.

\section{CONCLUSÃO}

Foram sintetizados, neste trabalho, quatorze derivados 5-nitro-2-tiofilidênicos que foram testados frente às cepas padrão e multi-resistente de Staphylococcus aureus. Constatou-se como composto mais ativo da série a 5-nitro-2-tiofilideno-4-acetilbenzidrazida (14), enquanto que o composto de mais baixa atividade foi a 5-nitro-2-tiofilideno-4-butilbenzidrazida (11). Os re- sultados obtidos para a cepa multi-resistente mostraram-se compatíveis com os determinados para a cepa padrão, sugerindo que a cepa de Staphylococcus aureus com caráter de multi-resistência utilizada, ainda não dispõe de mecanismos de detoxificação para os compostos estudados neste trabalho.

\section{ABSTRACT}

\section{Synthesis and determination of antimicrobial activity of 5-nitro-2-thiophylidene derivatives against MRSA}

Infection diseases caused by methicillin-resistant Staphylococcus aureus have been an increasing problem worldwide presenting significant morbidity and mortality rates. Thus, fourteen benzoic acid [(5-nitro-thiophen-2-yl)methylene]-hydrazides were designed, synthesized and tested against standard (ATCC 25923) and multidrug-resistant strains of Staphylococcus aureus. All compounds exhibited significant bacteriostatic activity and, in such cases, also bactericidal activity, especially the $\mathrm{p}-\mathrm{COCH}_{3}$ derivative with $M I C=0.14 \mathrm{mg} / \mathrm{mL}$. The results have demonstrated the 
potential of synthesized compounds as alternative to the development of selective antimicrobial agents.

UNITERMS: Staphylococcus aureus. Synthesis. MIC. Nifuroxazide. Multidrug-Resistance.

\section{AGRADECIMENTOS}

Agradecemos à CAPES e à FAPESP pelo suporte financeiro para o desenvolvimento deste trabalho. Agradecemos à Profa. Dra. Elsa Masae Mamizuka, coordenadora do LRNFSA do FBC/FCF/USP por ter gentilmente cedido a cepa $3 \mathrm{SP} / \mathrm{R} 33$ de $S$. aureus e todo o suporte técnico-científico para a realização dos ensaios. Agradecemos também a Profa. Dra. Thereza Christina VessoniPenna, coordenadora do LCIF do FBT/FCF/USP por ter cedido a cepa ATCC 25923 de Staphylococcus aureus e o suporte técnico-científico para a realização dos ensaios.

\section{REFERÊNCIAS BIBLIOGRÁFICAS}

BARREIRO, E.J.; FRAGA, C.A.M. Química Medicinal: as bases moleculares da ação dos fármacos. Porto Alegre: Artmed Editora, 2001. 83p.

BAUER,A.W.; KIRBY, W.M.; SHERRIS, J.C.; TURCK, M. Antibiotic susceptibility testing by a standardized single disk method. Am. J. Clin. Pathol., Chicago, v. 45, n. 4, p. 493-496, 1966.

BRENWALD, N.P.; FRAISE, A.P. Triclosan resistance in methicillin-resistant Staphylococcus aureus (MRSA). J. Hosp. Infect., Londres, v. 55, n. 2, p. 141-144, 2003.

BURD, M.; HUMPHRES, H.; GLYN, G.; MITCHELL, E.; MCDONALD, P.; JOHNSON, H.; MCDONNELL, B.; DOYLE, D.; ROSSNEY,A. Control and the prevention of methicillin-resistant Staphylococcus aureus in hospitals in Ireland: North/South study of MRSA in Ireland 1999. J. Hosp. Infect., Londres, v. 53, p. 297-303, 2003.

CAREY, F.A. Organic Chemistry. 4 ed. New York: Mc Graw-Hill, 2000. p. 572-677, 790-800.

COLLINS, C.H.; LYNE, P.M.; GRANGE, J.M. Collins and Lyne's microbiological methods. 7. ed. Oxford: Butterworth-Heinemann, 1995. 493p.

CRAIG, P.N. Interdependence between physical parameters and selection of substituent groups for correlation studies. J. Med. Chem., Columbus, v. 14, n. 8, p. 680-684, 1971.
CROWCROFT, N.S. Methicillin-resistant Staphylococcus aureus and antimicrobial use in Belgian hospital. Infect. Control Hosp. Epidemiol., Thorofare, v. 20, p. 31-36, 1999.

DAYAN, J.; DEGUINGAND, C.; TRUZMAN, C. Study of the mutagenic activity of 6 hepatotoxic pharmaceutical drugs in the Salmonella typhimurium microsome test, and the HGPRT Na+/K+ ATPase system in cultured mammalian cells. Mutat. Res., Amsterdam, v. 157, n. 1, p. 1-12, 1985.

DESAI, D.; DESAI, N.; NIGHTINGALE, P.; ELLIOT, T.; NEUBERGER, J. Carriage of methicillin-resistant Staphylococcus aureus is associated with an increased risk of infection after liver transplantation. Liver Transplantation, Los Angeles, v. 9, n. 7, p. 754-759, 2003.

FERNANDES, P.B.; MENZEL, R.; HARDY, D.J.; TSEDINH, Y.; WARREN, A.; ELSEMORE, D.A. Microbial resistance: novel screens for a contemporary problem. Med. Res. Rev., New York, v. 19, n. 6, p. 559-568, 1999.

FUCHS, P.C.; KOOP, J.; HAFNER, H.; KLEINER, U.; PALLUA, N. MRSA - retrospective analysis of an outbreak in the burn centre Aachen. Burns, Wiltshire, v. 28, p. 575-578, 2002.

HANSCH, C.; LEO, A. Exploring QSAR: fundamentals and applications in chemistry and biology. Washington: American Chemical Society, 1995. 557 p.

JONES, M.E.; BOENINK, N.M.; VERHOEF, J.; KOHRER, K.; SCHIMITZ, F..J. Multiple mutations conferring ciprofloxacin resistance in Staphylococcus aureus demonstrate long-term stability in an antibiotic-free environment. J. Antimicrob. Chemother., Oxford, v. 45, p. 353-356, 2000.

LIZIOLI, A.; PRIVITERA, G.; ALLIATA, E.; BANFI, E.M.A.; BOSELLI, L.; PANCERI, M.L.; PERNA, M.C.; PORRETTA, A.D.; SANTINI, M.G.; CARRERI, V. Prevalence of nosocomial infections in Italy: result from the Lombardy survey in 2000. J. Hosp. Infect., Londres, v. 54, p. 141-148, 2003.

MASUNARI, A.; NASCIMENTO, F.L.L.; FURLANETTO, M.; SANTOS, M.G.B.; VESSONI-PENNA, T.C.; MAMIZUKA, E. M.; TAVARES, L.C. Determinação da atividade antimicrobiana de derivados 5-nitro-2tiofilidênicos frente às cepas padrão e multi-resistente de Staphylococcus aureus. Rev. Bras. Ciênc. Farm, São Paulo, v. 39, p. 192-194, 2003. 
MASUNARI, A.; REZENDE, P.; TAVARES, L.C. QSAR studies of nifuroxazide analogs with antimicrobial activity against multidrug-resistant S. aureus In: The $15^{\text {th }}$ European Symposium on Quantitative Structure-Activity Relationships \& Molecular Modeling, 2004. Istanbul. Resumos de Trabalhos. Istanbul: Prous Science, 2004. p. 123.

MAUDSLEY, J.; STONE, S. P.; KIBBLER, C. C.; ILIFFE, S. R.; CONATY, S. J.; COOKSON, B. D.; DUCKWORTH, G. J.; JOHNSON, A.; WALLACE, P. G. The community prevalence of methicillin-resistant Staphylococcus aureus (MRSA) in older people living in their own homes: implications for treatment, screening and surveillance in the UK. J. Hosp. Infect., v. 57, n. 3, p. 258-262, 2004.

MCDONALD, P.; MITCHELLI, E.; JOHNSON, H.; ROSSNEY, A.; HUMPHREYS, H.; GLYNN, G.; BURD, M.; DOYLE, D.; MCDONNELL, R. Epidemiology of MRSA: the North/South study of MRSA in Ireland 1999. J. Hosp. Infect., London, v. 54, p. 130-134, 2003.

NISHI, J. Difference in incidence and transmission mode of methicillin-resistant Staphylococcus aureus among surgery, orthopedics, and pediatrics wards: a prospective study at a university hospital. Infect. Contr. Hosp. Epidem., Thorofare, v. 19, n. 2., p. 107-109, 1998.

OLIVEIRA, G.A.; DELL'AQUILA, A.M.; MASIERO, R.L.; LEVY, C.E.; GOMES, M.S.; CUI, L.; HIRAMATSU, K.; MAMIZUKA, E.M. Isolation in Brazil of nosocomial Staphylococcus aureus with reduced susceptibility to vancomycin. Infect. Contr. Hosp. Epidem., Thorofare, v. 22, n. 7, p. 443-448, 2001.

ONORATO, M. Risk factors for colonization or infection due to methicillin-resistant Staphylococcus aureus in HIV-positive patients: a retrospective case-control study. Infect. Contr. Hosp. Epidem., Thorofare, v. 20, n. 1, p. 26-30, 1999.

PETRI JR., W.A. Antimicrobial agents. In: HARDMAN, J.G.; LIMBIRD, L.E.; GILMAN, A.G. GOODMAN \& GILMAN'S: The pharmacological basis of therapeutics. 10 ed. New York: McGraw-Hill, 2001. 1171p.
REZENDE, P.; MASUNARI, A.; SANTOS, M. G. B.; MAMIZUKA, E. M.; VESSONI-PENNA, T. C.; TAVARES, L. C. Hansch Analysis of nifuroxazide analogues with antimicrobial activity against MRSA Barcelona, Drugs Fut., v. 27, p. 192-192. (Symposium on Medicinal Chemistry, 17., 2002).

ROHR, U.; MUELLER, C.; WILHELM, M.; MUHR, G.; GATERMAN, S. Methicillin-resistant Staphylococcus aureus whole-body decolonization among hospitalized patients with variable site colonization by using mupirocin in combination with octenidine dihydrochloride. J. Hosp. Infect., London, v. 54, p. 305309, 2003.

SOLOMONS, G.; FRYHLE, C. Organic Chemistry. 7 ed. New York : John Wiley \& Sons, 2000. p. 738-740, 829831, 838-843.

TAVARES, L.C. Relações quantitativas entre a estrutura química e a atividade antimicrobiana de análogos a nifuroxazida. São Paulo, 1993. 186p. Tese de Doutorado - Faculdade de Ciências Farmacêuticas - Universidade de São Paulo.

TAVARES, L.C.; CHISTÉ, J.J.; SANTOS, M.G.B.; PENNA, T.C.V. Synthesis and biological activity of nifuroxazide and analogs II. Boll. Chim. Farm., Milano, v. 138, n. 8, p. 432-436, 1999a.

TAVARES, L.C.; MILANI, S.R.; RODRIGUES, A.M.; SANTOS, M.G.B.; PENNA, T.C.V. Síntese e determinação da atividade antimicrobiana de derivados do 5-nitro-2-furfurilideno. Rev. Farm. Quim., São Paulo, v. 32, n. 1, p. 44-48, 1999 b.

TAVARES, L.C.; PENNA, T.C.V.; AMARAL, A.T. Synthesis and biological activity of nifuroxazide and analogs. Boll. Quim. Farm., Milano, v. 136, n. 3, p. 244249, 1997.

TOPLISS, J.G., Utilization of operational scheme for analog synthesis in drug design J. Med. Chem., Columbus, v. 15, n. 10, p. 1006-1010, 1972.

WERMUTH, C.G. The Practice of Medicinal Chemistry. London: Academic Press, 2000. 768p.

Recebido para publicação em 08 de agosto de 2005. Aceito para publicação em 16 de março de 2006. 